\title{
Mistrust and refugee women who are lone parents in resettlement contexts.
}

\author{
Abstract \\ The theme of mistrust in resettlement contexts is largely overlooked in refugee \\ discourses. Through a qualitative inquiry of post-migration experiences of four women \\ raising children alone in Brisbane, Australia, this paper outlines how the presence of \\ mistrust could at times create difficult resettlement circumstances for these women, who \\ then needed to negotiate additional obstacles in everyday life. The definition of social \\ mistrust used here is a form of deliberate and ongoing suspicion about lone refugee \\ women's choices and lifestyles from other community members. Importantly, the \\ women achieved a sense of wellbeing despite experiencing mistrust, both in inter-group \\ and intra-group contexts, indicating that they conceptualised access to and benefits from \\ social networks with different emphases on trust. \\ Socio-cultural narratives of mistrust, particularly gender-specific perspectives \\ can enrich refugee discourses, and challenge established notions of trust inherent to \\ understandings of social networks in resettlement. The findings discussed in this paper \\ contribute to debunking the 'myth' of homogeneity in relation to refugee groups and \\ demonstrate the diversity of experiences among sub-groups of refugee women. The \\ theme of mistrust, particularly among women, is an oft-neglected aspect and requires \\ further attention.
}

Keywords: Mistrust, refugee women, social networks, resettlement, wellbeing. 


\section{Mistrust and refugee women who are lone parents in resettlement contexts.}

'Trust dies but mistrust blossoms'.

Sophocles (497-406/5 B.C.)

\section{Introduction}

Dawn (pseudonym) is a widowed refugee woman who lives in Brisbane and raises five children by herself. As illustrated through Dawn's quote below, the impact of experiencing mistrust from members of her local community, that is, people from the same country of origin and language group, significantly affected her wellbeing during the resettlement process in the Australian context:

It is really challenging, even in the community, they can really say something, nobody will listen to you, because they just think you are a single woman. When you are successful, you work, you educate your children, like myself, I did everything, all I could to educate my children. I don't know if it is jealousy or anything, instead of appreciating as a single woman manage to do all that, now they've come up with strange stories, they don't believe that I can do that. They say, maybe there is a man behind [laughs], she can't do that by herself, it's impossible, no woman can do that. So that's what I've heard several times and some people they have even confronted me. (Dawn) 
To do justice to the complexity of diverse situations that refugee women may navigate in resettlement contexts, different constructs are needed to unpack various dimensions of these experiences (for instance, Vervliet, De Mol, Broekaert, and Derluyngiven, 2013). Mistrust is one such multifaceted concept with varying implications for marginalised groups like refugee women. The theme of mistrust is of particular relevance to refugee populations given the disruptive and stressful nature of events that can lead people to seek asylum (N1'Raghallaigh, 2013). Yet, Miller (2004) qualifies as 'puzzling' the lack of discussion on trust, and by extension, on mistrust, in the refugee mental health literature despite its pertinence. Conceptualisations of mistrust should therefore gain a more central place in refugee research as new understandings emerge.

Social trust generally refers to trust in people, while mistrust is usually conceptualised as a lack of trust towards the unknown (Frederiksen, 2011). While refugees as a broad 'group' can at times experience mistrust in resettlement contexts, the focus of this paper is on the specific lived realities of refugee women who were either divorced or widowed, and whose experiences of mistrust occurred mainly because of their marital status. By understanding how refugee women experience trust and mistrust intra-group as well as inter-group, current resettlement discourses can better reflect the realities of those who are excluded due to strong social networks (Siegmann and Thieme, 2010). Based on refugee women's accounts documented 
through a combination of qualitative methods, this paper outlines how experiences of mistrust could categorise the women as 'outsiders', regardless of their ongoing efforts to navigate a range of situations while resettling to Australia.

A fundamental question raised here is that, if trust is the 'social lubricant' enabling access to collective resources (Wang, Schlesinger, Wang and Hsiao, 2009), then what of individuals who are 'denied' trust as part of intra- and inter-group experiences and are thus ostracised from their own communities? Importantly, Carpenter, Daniere and Takahashi (2004) draw links among trust, reciprocity and cooperation, and people's quality of life and wellbeing, meaning that experiences of mistrust are inextricably linked to mental health outcomes. Wellbeing is defined here as one's '[s]ocial, economic and political circumstances, class, age, gender, family structure, support networks and community capacity' (Manderson, 2005a: 4). The findings discussed in this paper not only demonstrate the benefits from accessing high levels of 'trust', but also highlight how individuals such as lone refugee women negotitate social mistrust and still manage to achieve a sense of wellbeing. Thus, gender-specific accounts of mistrust provide a nuanced understanding of the dynamics and the exclusionary outcomes that can sometimes characterise strong networks. Sociocultural narratives of mistrust therefore deserve further attention in refugee discourses, particularly in resettlement settings. 
The paper begins by discussing the emerging body of literature on the theme of mistrust. Then, narratives of intra- and inter-group trust and mistrust among a small group of refugee women who are lone parents highlight how these women could face significant hardships through exclusion, thus keeping them at the margins of social networks. This proposition enriches the refugee literature since it indicates how lone refugee women conceptualised aspects of their resettlement experiences with different emphases on trust and mistrust to perhaps what others might encounter. In the women's pursuit of building a new life for their families in a new country, participants resorted to developing distinct strategies to navigate attitudes based on mistrust of them as lone parents. This paper contributes a novel outlook on resettlement settings by focussing on inter-group as well as intra-group mistrust, as this aspect tends to be generally overlooked in discussions on social networks.

\section{Mistrust}

Strong group bonds can reduce acceptance of outsiders and create suspicion and mistrust. In fact, the very existence of networks relies of the exclusion of others and thus perpetuates unequal power dynamics (Siegmann and Thieme, 2010). The definition of social mistrust adopted here, based on the experiences of lone refugee women, is a form of deliberate and ongoing suspicion about the women's life choices from other community members. While the current body of literature on mistrust is relatively sparse, a few qualitative explorations of mistrust provide useful perspectives for this 
discussion. For example, Wang et al. (2009: 134) argue that mistrust is not simply the opposite of trust, since '[c]onceptually, mistrust carries different emotional and cognitive implications from the absence of trust'. These authors argue that concepts denoting lack of trust and mistrust cannot be used interchangeably as is often the case in existing research. Indeed, a lack of trust prevailing across several villages in China had different consequences for health outcomes when compared to the impact of mistrust (Wang et al., 2009). The same was true concerning the distinct impacts of trust and mistrust on mental health outcomes.

The concept of mistrust, particularly in relation to how social networks function, is slowly gaining more attention in the literature (for instance Brown, 2007; Uslaner, 2010). This growing trend shows that it is not 'uncommon' to situate feelings of mistrust as integral to many people's everyday lives. However, current discussions posit mistrust as a predominantly inter-group phenomenon. For instance, this can be seen in Uslaner's (2010) discussions on diversity, segregation and mistrust in Western settings with growing migrant populations, which shed light on the assumptions and links among these highly complex and contested concepts. An inter-group emphasis also guided Thorburn et al.'s (2012) analysis of medical mistrust and discrimination among a small group of Hmong people in the United States, which focussed on cultural distance and unfamiliarity between community members and Anglo-Saxon doctors. 
In another example, a recent study on mistrust and unaccompanied asylumseeking minors living in the Republic of Ireland (N1'Raghallaigh, 2013) highlighted that this group's difficulty to trust was inextricably linked to their pre- and post-migration contexts. Mistrust was described as what Miller (2004, p. 217) calls 'a self-protective insularity', or in other terms, a coping mechanism. Here too, general feelings of trust and mistrust were not specifically linked to intra-group experiences in resettlement, but referred primarily to pre-migration contexts, or inter-group relations involving the broader Irish community. Based on such explorations, existing discourses may yield an erroneous impression that mistrust is only ever present when individuals are vastly different from one another. As the discussions in this paper suggest, in reality, there can be as much mistrust intra-group as there is inter-group.

An important exception that is pertinent here is Brown's $(2006 ; 2007)$ explorations of rural African American women's social networks, which revealed that mistrust of other women was a significant theme for women who used drugs. Other studies on the social networks of drug-using women had identified mistrust as an important narrative (Henderson and Boyd, 1997; Lichtenstein, 2001) without, however, elaborating on the causes for this trend. In contrast, Brown identified that such women's social networks were kept relatively small due to specific concerns that justified their mistrust of other women, ranging from lack of trustworthiness, to feeling more comfortable around men generally. Hence, the small size or non-existence of social 
networks was clearly in response to drug-using women's feelings of mistrust towards other women. Brown (2007: 1158) concluded that mistrust among women was a 'poorly understood phenomenon', requiring further attention across various settings. Brown's analysis thus highlights the paucity of research on socio-cultural narratives of mistrust generally, let along among seemingly homogenous groups.

\section{Social Networks in Resettlement}

The links between trust and mistrust and social networks receive limited attention (Igarashi et al., 2008), perhaps due to the predominant focus of discussions pertaining to trust in relation to social capital. While trust is a quintessential element of social capital discourses, existing research is often criticised for its ambiguous, simplistic and inconsistent application and measurements of concepts of trust (Wang et al., 2009). Nevertheless, this paper does not intend on providing an extensive discussion on the contested concept that is social capital. Suffice it to say that firstly, social capital debates are slowly acknowledging socio-cultural factors pertinent to resettlement as part of broader analyses (for instance Brettell, 2005); secondly, increasingly more attention is paid to 'gendered' social capital (Healy, Haynes and Hampshire, 2007; Siegmann and Thieme, 2010), although literature on such dynamics is still sparse. Hence, there is some indication that dominant understandings of trust and mistrust in that particular context might be shifting. 
Importantly, the presence of social networks is inextricably linked to migration discourses, the assumption being that stronger networks equate to less vulnerability in resettlement (Siegmann and Thieme, 2010). For instance, in Morrice's (2007) study of resettled refugees in the UK, these individuals mostly trusted other refugees to 'get by' in a new country, while they generally lacked the connections outside their community to pursue further educational and career paths (Morrice, 2007). However, there is an underlying assumption that low-income environments, such as those produced through resettlement, are characterised by a lack of trust and cooperation, when in fact it is access to political influence and economic capital that is limited (Carpenter et al., 2004). In fact, very high levels of trust and co-operation as found in two South-east Asian cities were attributed to stable, low-income communities whose socio-economic circumstances created a collaborative approach to opportunities and challenges over time (Carpenter et al., 2004). Hence, close family ties and community groups in resettlement act as resources for refugees to find employment and establish themselves (Lamba, 2003). Different compositions of social networks can thus produce nuanced conceptualisations of trust, particularly when the heterogeneity of groups is acknowledged.

Indeed, ethnic networks are often viewed as culturally homogeneous, yielding a distinct, unproblematic form of support. Such perspectives disregard intra-group power relations and potentially adverse impacts on individuals (Shah, 2007). High levels of 
trust are often preserved for in-group members (Sanders, 2002), and this has obvious implications for individuals who are ostracised within, thus creating a minority inside a minority. Yet, the literature overlooks intra-group conflicts of interests among migrants and refugees (McMichael and Manderson, 2004); the example of Bosnian immigrants who were expected to connect with Serbian and Croatian resources when they came to Australia in the 1990s is a case in point. Since existing networks may prove exclusive of newly formed communities, established ethinic networks may represent an additional barrier to their resettlement. Thus, qualitative explorations of issues of mistrust specifically, further challenge underlying assumptions of homogeneity among refugee social networks.

Finally, the objective of having a gendered analysis of migration processes has rarely been achieved (Curran et al., 2005), because of assumptions of homogeneity of emerging issues for all women, which can be inaccurate (Phan, Torres Rivera, and Roberts-Wilbur, 2005). While women in refugee camp situations have limited options due to restricted social interactions and loss of social and economic lives (Boateng, 2010), different challenges emerge in resettlement countries like Australia (see McMichael, 2002; McMichael and Manderson, 2004; Paul, 1999). Furthermore, gender relations differ in public and private arenas, with women relying more on informal social networks due to limited access to resources. Consequently, 'women in general would be more likely to engage in trust, reciprocity and co-operative relationships than 
men' (Carpenter et al., 2004: 857). This point clearly establishes the importance of gender-specific narratives in considering issues of trust and mistrust in resettlement.

\section{Study Overview}

The findings reported here emerged from a small study on four refugee women's perspectives on resilience and wellbeing in Brisbane, Australia. The author conducted ethnographic fieldwork over approximately 12 months in 2008 and 2009 to seek contextual understandings of mental health concepts. Ethical clearance was granted from the Queensland University of Technology's Human Research Ethics Committee. The study's broader findings were reported elsewhere (Lenette, Brough and Cox, 2013; Lenette and Boddy, 2013).

An ethnographic approach was used to contextualise the everyday experiences of this group of women, and allowed for detailed descriptions of gender-specific wellbeing discourses. Qualitative data was collected using a combination of participant observation, in-depth interviews, photo-voice and digital storytelling. Observations of the women's homes, workplaces, and community gatherings in the Brisbane area were recorded regularly to complement data collected through interviews, photos and digital stories. Such observations focussed on the women's interactions with family members, colleagues, and local community members. Concurrently, the interviews and visual ethnographic methods retraced the women's journeys from their respective home 
countries to their current life in Australia, and the daily challenges and opportunities they encountered in resettlement. These methods were not only chosen to convey depth and richness of themes that could at times be of a sensitive nature, but also because they are particularly appropriate for collaborating with marginalised groups like refugee women (Harper, 2002; Lenette et al., 2013).

An intersectional approach that recognises women's complex experiences in diverse contexts (Samuels and Ross-Sheriff, 2008; Vervliet et al., 2013) was used to analyse the data collected through this combination of qualitative methods. Not only does this theoretical perspective acknowledge how interconnected issues such as gender, age, socio-economic status or religion have a compound effect (Pittaway and Bartolomei, 2001), but it is also 'particularly suited to convey nuanced understandings of participants' social worlds' (Lenette and Boddy, 2013, p. 86). Intersectionality therefore allowed for a multi-faceted analysis of the participants' narratives collected through interviews and visual ethnographic methods, combined with observations. Hence, the aim of this study was not to generalise findings to a whole group of refugee women, but to report on the subjective experiences of a small sub-group. While a total of eight women were initially approached for participation in this project, only four women were able to continue for the whole duration of fieldwork. The small number of participants in this study enabled in-depth exploration of plural pathways to resilience. 
Participants were engaged using purposive sampling combined with the 'snowball' technique when possible. The women resided in the Brisbane area. Two participants were widows, were proficient in English and were in paid employment, whereas two others were divorced, had limited English language abilities and were unemployed. The women with limited English language abilities were still able to fully participate in this project; one was a community-based bilingual volunteer and therefore had an adequate command of English to communicate with the author. The other participant spoke in French, which happened to be the author's first language. This woman's contributions were then recorded as field notes in English using verbatim translation. All came from African countries and were aged from their late thirties to early fifties. Participants cared for between one and seven children as lone parents. Pseudonyms were assigned to each participant to ensure confidentiality and details are summarised in Table 1 below. 
Table 1

Demographic information on four participants

\section{Participant Demographic Information}

Age range

Marital status

Country of origin

English Proficiency

Number of children and

dependents

Time in Australia

Educational level
30-55 years

Widowed (2 participants)

Divorced (2 participants)

Sudan (2 participants)

Burundi (1 participant)

Democratic Republic of Congo (1 participant)

Excellent (2 participants)

Limited (2 participants)

Zena ( 7 children +3 dependents)

Dawn (5 children)

Patience ( 1 child +2 dependents)

Evelyn (5 children)

Zena (2 years)

Dawn (2 years)

Patience (2 years)

Evelyn (5 years)

Tertiary level (2 participants) 
Vocational (1 participant)

Unstated (1 participant)

Employment

Employed (2 participants)

Unemployed (2 participants) 
Data collection and in-depth thematic analysis were ongoing and iterative. Thus, participants' narratives yielded 'thick' ethnographic description (Geertz, 1973) of gender-specific conceptualisations of resilience. Three participants agreed to have follow-up interviews audio-recorded to confirm emerging findings.

\section{Findings}

\section{Trust Within}

All four women in this study felt that, in many respects, without the help of their local communities, they would be lost. The trust participants expressed towards some members was integral to their sense of wellbeing. The refugee women generally sought to integrate local communities, particularly for their children's benefit. The community came together and helped with key initial resettlement procedures, such as opening bank accounts, registering with the Australian Government Department of Human Services' Centrelink, enrolling children at school, or learning to do grocery shopping. This occurred without any expectation of financial contribution in return.

For example, community members would drive Patience to appointments without asking for money to cover petrol costs, while Evelyn recounted how her children and herself lived with another family for about four months, and were not required to pay any rent (although she contributed to grocery shopping bills). The community also came together in times of hardship. Patience reminisced how at the 
news of her aunt's death in her country of origin, money was collected to assist with funeral expenses; anyone considered an adult within the community was expected to contribute. Hence, all four participants relied heavily on family ties and community connections as sources of support particularly during initial resettlement stages.

\section{Intra-Group Mistrust}

Many isolated women felt they were excluded or stigmatised within their local communities because of their marital status. Lone mothers in particular encountered social mistrust because of underlying assumptions that they were 'unfit' women. For instance, Dawn recounted how her choice of raising children without remarrying after she became a widow made her an easy target for community gossip:

Being a single mother, maybe this is the worst part of it, when you are being seen or associating or working or communicating with other men who are married, automatically they assume that you are running after their men, particularly here in Australia. That has affected me so much to the stage that I really keep away from associating with other people's husband. (Dawn)

Experiencing mistrust from the community was a source of distress for unmarried women, as Dawn explained, “The moment you are seen twice moving with someone's husband you'll be approached that you're trying to befriend a man... So that has been difficult for me and most of the single mothers here". Evelyn was in a similar situation 
as a widow raising children by herself; she found interactions within her local community challenging because she decided not to re-marry: "Sometimes, it is so hard to understand community dynamics, there's gossips, fighting, ignorance, and it makes it difficult with coping with day-to-day activities and challenges”.

Dawn recounted how unsupportive some community members were of lone women's choices to remain unmarried and raise children by themselves, openly wishing them to fail at this task:

In fact being single, the community sometimes they consider that a woman, that is just a perspective or a belief they have, that a woman cannot bring up children, because they consider women as the weaker person or the weaker sex, that can't manage a lot of things. (Dawn)

The women's trust towards some community members was thus often challenged. Refugee women raising children alone found themselves in situations where they had limited interactions with people from the same country of origin and language group due to community tensions about their marital status, and therefore had no other choice than to remain isolated.

For example, Zena and Patience had purposefully moved away from the suburbs where most of their local community members lived, as they both thought it would be 'terrible' to live in such close proximity to everyone. There were too many community tensions and extensive gossip, which made their day-to-day life difficult at times. 
Consequently, both women stood firm on their decision to live a few suburbs away, despite some of the difficulties this context also entailed for them and their children, such as limited public transport options and further distance to travel to work.

Concurrently, while refugee women like Dawn and Evelyn struggled with certain aspects of community life, they remained largely unfazed by people's attitudes in terms of achieving their goals. Ambivalent sentiments towards the nurturing and detrimental aspects of community life were inextricably linked to the women's sense of wellbeing. Nevertheless, local community members' attitudes towards lone refugee women certainly had a significant impact on them, as conveyed by Dawn's words:

For me, mentally, it affects so much, on myself sometimes I think 'Why is this happening to me? Is it because I'm single, people don't appreciate what you do, people don't recognise what you do. You become so stressed, so frustrated and sometimes even you hate participating in some community events, and sometimes even when we are there, you start hearing this bad gossip behind your back, it is so stressful. Most of the single women are stressed and depressed because of that. Every now and then there is some accusations. (Dawn)

As a result of such attitudes, participants did not always trust that members of their local communities had the women's best interests in mind. For instance, the women could make up excuses to get out of commitments they felt were imposed upon them, or when they did not feel like being questioned about particular aspects of their lives. Finding 
excuses represented an easier alternative than explaining their reticence to trust fellow community members, as they did not want to create tensions or come across as ungrateful.

\section{Trust Beyond}

While resources derived from networks external to ethnic groups can be overlooked in the resettlement literature, the women's narratives reinforced that trust and reciprocity were often established outside local communities. While integrating their own communities was important, Evelyn and Zena identified how the involvement of someone 'outside' their local communities was equally significant, having an enormous impact on the adaptation process.

Evelyn recalled vividly how her Techincal And Further Education (TAFE) English teacher encouraged her to apply for a job by assisting with the application and interview process, and by providing emotional support and mentoring. She expressed strong feelings of attachment for this teacher and spoke fondly of her. Evelyn felt she owed her successful work life and motivation to study at university to this teacher. She would not have received the same level of encouragement and support from her local community members towards employment and further studies, thus being greatly disadvantaged. In fact, Evelyn said that she would have been mostly discouraged to work or study as a lone parent. 
Zena also remembered how a TAFE classmate was the first person to help her learn English in a practical sense. She was surprised that a White Australian woman would show interest and want to help her overcome the language barrier. During fieldwork, Zena's neighbour (also a lone parent) helped her settle in a new neighbourhood and improve her conversational English skills. She expressed amazement at her 'lovely Australian' neighbour's willingness to get involved despite barely knowing Zena.

\section{Inter-Group Mistrust}

Issues of social mistrust were not limited to the women's local communities but extended to parts of mainstream Australian community as well. Lone refugee women like Dawn and Evelyn made conscious efforts to create relationships outside their local communities specifically because of the benefits of such links to work and study prospects. However, it was often difficult to develop such connections because of broader community members' exclusionary attitudes. Patience, Dawn and Evelyn all reported hostility from neighbours (who were mostly White Australians), and Zena expressed disappointment at only having a distant relationship with those who were barely civil to her and her children.

Evelyn and Dawn mentioned incidents motivated by racism at work (although they did not feel hugely affected by these, having experienced such situations many times). Concurrently, Patience and Zena felt isolated and limited by their limited 
English language abilities. At the same time, all four women were apprehensive of outgroup influences (which they referred to as 'the Australian culture') on their children, minimising the likelihood of the women pursuing relationships in the social sphere in mainstream Australian community. Thus, the women were not always sure whom they could trust within or beyond their local communities.

\section{Discussion}

\section{Refugee Women at the Margins}

The resettled women's narratives highlight the presence of trust and mistrust in their everyday realities. While all four participants encountered trust and mistrust intraand inter-group, the findings indicate a stronger emphasis on how the dynamics within local communities were a bigger source of mistrust, and thus clearly impacted on the women's wellbeing more significantly. This theme represents a significant aspect of resettlement discourses, which to date, has been largerly absent. A key implication that informs nuanced understandings of refugee experiences in resettlement, is that women raising children alone and whom their community as well as broader society did not fully trust, could face significant hardships, thus increasing their vulnerabilities and keeping them at the margins of their communities.

It is true that the literature usually presents social networks as inherently good, as the source of information, trust, support and relationships in resettlement (McMichael and Manderson, 2004). For instance, Balatti and Falk (2002) found that a 
group of African refugee women from an English as Second Language (ESL) class in Melbourne developed a new identity based on commonalities, leading the women to access new resources. By participating in class, they acquired skills to do their own banking, catch public transport, and access services. The women 'had to relearn to trust people and systems in their new country [and] learn a new identity' (Balatti and Falk, 2002: 293). Yet, discussions of trust tend to neglect broader socio-cultural factors (Shah, 2007) and the tensions that can characterise community dynamics and politics, as illustrated by participating women's quotes.

Strong social netwoks can equally be the source of anxiety and issues for those disadvantaged and ostracised by tight knit groups' structures and embedded norms. For example, there were distinct gender patterns in South-American migrants' employment opportunities in the United States as a result of accessing social networks: women tended to be confined to unregulated domestic work, while their male counterparts secured better jobs (Siegmann and Thieme, 2010). Further, Iraqi women in rural Victoria faced difficulty integrating the Iraqi as well as mainstream communities due to tensions in both contexts, resulting in 'an acute sense of displacement relating to 'not fitting in'(Manderson and Vasey, 2009: 240). Some Iraqi women purposely isolated themselves from other community members, including other women, with limited opportunities for interactions outside formal social obligations - as was the case for 
women in the study under discussion. Thus, further critical outlooks on trust and mistrust in resettlement settings are warranted.

The four women in this study generally trusted community members to assist them in adapting to vastly different environments, particularly during the initial resettlement stages. Culturally prescribed obligations were inherent to the women's narratives of wellbeing. Yet, high levels of intra-group trust also yielded a sense of mistrust to the detriment of lone refugee mothers who were considered 'out-group' based primarily on their marital status. Clearly, women who raised children alone were not always trusted; they faced suspicion from local community members as to their intentions towards male members of the community (married or unmarried). They also reported how people in their surroundings expressed doubts about the women's abilities to raise children 'properly' on their own. Participants were at times hurt by such mistrust from people from their own country or language group, and this could affect the refugee women's sense of self-worth.

Thus, women who are ostracised and excluded intra-group may need to devise different strategies in order to move onwards (see Siegmann and Thieme, 2010 for examples in development contexts). This is similar to Miller's (2004) notion of 'selfprotection', as situations of mistrust enabled these refugee women to persevere towards their goals, regardless of community support. The lone refugee mothers discussed here had to develop novel avenues to navigate through the opportunities and challenges of 
resettlement, in the absence of feelings of mutuality and trust from some local community members. Such instances included developing key relationships beyond local communities, while at the same time, carefully negotiating community dynamics that could have detrimental outcomes for their wellbeing, without however segregating themselves and foregoing the benefits derived from community participation. This situation was specific to lone refugee women and some particular dimensions may not be apparent among married women or refugee men generally. Thought of in this manner, resettlement may not be concerned that much about how to access or benefit from 'trust' (as in Peled and Leichtentritt, 2002), but how to navigate social mistrust and still manage to achieve a sense of wellbeing.

Certainly, situations of intra-group mistrust yield greater impetus to develop networks outside local communities. Participating women were more inclined than other community members to access broader opportunities to achieve resettlement goals like employment and further studies. Mistrust acted as a 'push factor' for women to develop external relationships to achieve their work and study goals. While gender differentials are said to increase women's vulnerabilities (Siegmann and Thieme, 2010), the lived experiences of refugee women in this study demonstrate how they were determined to overcome obstacles and achieve their aims regardless of their local communities' attitudes towards them. Further, Barnes (2001: 407) found that some resettled refugees in Australia 'find themselves in situations where their efforts and 
potential were recognized by individual Australians who were able to negotiate access to resources for them'. The lone refugee women discussed here spoke warmly of significant people outside their local communities, whom they learnt to trust. Overall, the women did not abandon their goals in the face of mistrust within local communities, but sought external avenues to progress.

Qualitative explorations of how refugee women manage issues of trust and mistrust specifically, further challenge the underlying assumption of homogeneity prevailing within refugee groups. Participants experienced resettlement differently to the rest of their local communities due to their marital status, as the women did not always trust that their circumstances were understood. In a similar example, Somali women in Melbourne did not always trust fellow community members to have their needs met, and felt a deep sense of frustration, isolation and disappointment (McMichael and Manderson, 2004). This was also the case for a couple of participants here who identified the inability of some community members to act in the women's best interests as a barrier to wellbeing. Thus, the women could at times 'bear the brunt' of strong social networks while being excluded from the benefits derived from such connections. They were not always trusted and neither did they trust their communities.

Importantly, idealising immigrant life from an outsider perspective and assuming homogeneity of experiences shift the attention away from gender and intragroup power imbalances (McMicheal and Manderson, 2004). Among Melbourne's 
Somali community, tight knit networks were beneficial in seeking employment and housing, accessing services, gaining information about opportunities and immigration processes, or securing bank loans. However, conflicts and hostilities that eroded trust, reciprocity and cohesion during wartime still informed social relations after resettlement, affecting women the most. Thus, the findings explored in this paper reinforce the gendered processes of resettlement. The manner in which the refugee literature is currently conceptualised, even when a gender analysis is provided, renders some women invisible. Examining mistrust towards a sub-group of refugee women further sheds light on intra-group dynamics, and challenge assumptions of homogeneity (as in Phan et al, 2005). The findings from this paper also contribute to the body of research from Brown $(2006 ; 2007)$ which considers the reasons underpinning mistrust among women. There is certainly scope to further examine the processes and intricacies linked to social networks among distinct groups.

\section{Conclusion}

The implications outlined here should prompt critical reconceptualisations of notions of trust in relation to resettlement. Ethnographic accounts can provide nuanced and gender-specific descriptions of experiences of trust and mistrust in resettlement contexts, as processes fostering trust or reinforcing social mistrust and their impacts can be more visible through qualitative narratives. The gender-specific experiences outlined in this paper reinforce the need to adopt a critical lens on the workings of resettlement 
processes to reveal their complex dimensions. The intricate and fluid notions of trust and mistrust, and their role in creating a sense of wellbeing, support Ní Raghallaigh's (2013) argument that more focus should be placed on exploring the exclusionary outcomes of social networks among refugee communities.

Rebuilding networks post-migration can be complicated; it is not a 'natural' process for resettled communities (McMichael and Manderson, 2004). Yet, even in circumstances of civil disruption and violence, some of the social trust that binds a community together may not be completely lost in exile (Manderson, 2005b). Moreover, the existence of informal networks often provides an alternative to the absence of economic or human capital (Morrice, 2007). As seen in this discussion, migrants and refugees are often disadvantaged, and intra-group variations in age, gender, power relations and history can create more disadvantaged subgroups (Manderson, 2005b). Thus, socio-cultural narratives of mistrust in participants' everyday lives testify to the women's ability to renegotiate trust and navigate through the sense of mistrust surrounding their circumstances. Participants had to carefully consider the presence of strong social networks as they managed tensions and opportunities in daily life in Australia, as the women did not take it for granted that they would benefit from it. 


\section{References}

Balatti, J and Falk, I (2002) Socioeconomic contributions of adult learning to community: A social capital perspective. Adult Education Quarterly, 52(4): 281298.

Barnes, D (2001) Resettled refugees' attachment to their original and subsequent homelands: Long-term Vietnamese refugees in Australia. Journal of Refugee Studies, 14(4): 394-411.

Boateng, A (2010) Survival voices: Social capital and the well-being of Liberian refugee women in Ghana. Journal of Immigrant and Refugee Studies, 8(4): 386408.

Brettell, CB (2005) Voluntary organizations, social capital, and the social incorporation of Asian Indian immigrants in the Dallas-Fort Worth metroplex. Anthropological Quarterly, 78(4): 853-883.

Brown, EJ (2006) Why rural African-American women who use cocaine mistrust women: The insider perspective. Journal of Psychosocial Nursing \& Mental Health Services, 44(4): 36.

Brown, EJ (2007) African-American women's exclusion of women and inclusion of kin and males into their social networks: A mistrust of women issue? Issues in Mental Health Nursing, 28(10): 1157-1157.

Carpenter, JP, Daniere AG and Takahashi, LM (2004) Social capital and trust in South- 
east Asian cities. Urban Studies, 41(4): 853-874.

Frederiksen, M (2011) Distrust and mistrust: Lessons from a low trust minority. Comparative Sociology, 10(2): 248-280.

Geertz, C (1973) The interpretation of cultures: Selected essays. New York: Basic Books.

Harper, D (2002) Talking about pictures: A case for photo elicitation. Visual Studies, 17(1): 13-26.

Healy, K, Haynes, M and Hampshire A (2007) Gender, social capital and location: understanding the interactions. International Journal of Social Welfare, 16: 110118.

Henderson, D and Boyd, C (1997) All my buddies was male: Relationship issues of women with addictions. The Association of Women's Health, Obstetric, and Neonatal Nurses, 26(4): 469-476.

Igarashi, T, Kashima, Y, Kashima, ES, Farsides, T, Kim, U, Strack, F, Werth, L and Yuki, M (2008) Culture, trust, and social networks. Asian Journal of Social Psychology, 11(1): 88-88.

Lamba, NK (2003) The employment experiences of Canadian refugees: Measuring the impact of human and social capital on quality of employment. Canadian Review of Sociology and Anthropology, 40(1): 45-64. 
Lenette, C and Boddy, J (2013) Visual ethnography: Promoting the mental health of refugee women. Qualitative Research Journal,13,1: 72-89.

Lenette, C, Brough, M and Cox, L (2013) Everyday resilience: Narratives of single refugee women with children. Qualitative Social Work, 12(5): 637-653.

Lichtenstein, B (2001) Women and crack-cocaine use: A study of social networks and HIV risk in an Alabama jail sample. Addiction Research, 5(4): 279-296.

Manderson, L (2005a) The social context of wellbeing. In: L. Manderson (Ed.), Rethinking Wellbeing (pp. 1-12). Perth: API Network.

Manderson, L (2005b) Social capital and inclusion: Locating wellbeing in community. In: L. Manderson (Ed.), Rethinking Wellbeing (pp. 21-28). Perth, Australia: API Network.

Manderson, L and Vasey, K (2009) Cooking alone: Social capital and wellbeing among Iraqi women refugees in Rural Victoria. In: G. Woolcock, and L. Manderson (Eds.), Social capital and social justice: Critical Australian perspectives (pp. 204-229). Darwin, Australia: Charles Darwin University.

McMichael, C (2002) 'Everywhere is Allah's Place': Islam and the everyday life of Somali women in Melbourne, Australia. Journal of Refugee Studies, 15(2): 171188.

McMichael, C and Manderson, L (2004) Somali women and well-being: Social networks and social capital among immigrant women in Australia. Human 
Organization, 63(1): 88-99.

Miller, KE (2004) Beyond the frontstage: Trust, access, and the relational context in research with refugee communities. American Journal of Community Psychology, 33(3/4): 217-227.

Morrice, L (2007) Lifelong learning and the social integration of refugees in the UK: The significance of social capital. International Journal of Lifelong Education, 26(20): 155-172.

NíRaghallaigh, M (2013) The causes of mistrust amongst asylum seekers and refugees: Insights from research with unaccompanied asylum-seeking minors living in the Republic of Ireland. Advance Access published March 2013. Journal of Refugee Studies 1-19.

Paul, F (1999) English acquisition and mental health for Somali women. In: B.

Ferguson, and E. Pittaway (Eds.), Nobody wants to talk about it: Refugee women's mental health (pp. 31-39). NSW, Australia: Transcultural Mental Health Centre.

Peled, E and Leichtentritt, R (2002) The Ethics of Qualitative Social Work Research. Qualitative Social Work, 1(2): 145-169.

Phan, LT, Torres Rivera, E and Roberts-Wilbur, J (2005) Understanding Vietnamese refugee women's identity development from a sociopolitical and historical 
perspective. Journal of Counseling and Development, 83(3): 305-312.

Pittaway, E and Bartolomei, L (2001) Refugees, race and gender: The multiple discrimination against refugee women. Refuge: Canada's Periodical on Refugees, 19(6): 21-32.

Samuels, GM and Ross-Sheriff, F (2008) Identity, oppression, and power: Feminisms and intersectionality theory. Affilia: Journal of Women and Social Work, 23(1): $5-9$.

Sanders, JM (2002) Ethnic boundaries and identity in plural societies. Annual Review of Sociology, 28(1): 327-357.

Shah, B (2007) Being young, female and Laotian: Ethnicity as social capital at the intersection of gender, generation, 'race' and age. Ethnic and Racial Studies, 30(1): $28-50$.

Siegmann, KA and Thieme, S (2010) Coping at women's expense: Social capital vulnerability links through a gender lens. Current Sociology, 58(5): 715-737.

Thorburn, S, Kue, J, Keon, KL and Lo, P (2012) Medical mistrust and discrimination in health care: A qualitative study of Hmong women and men. Journal of Community Health, 37(4): 822-829.

Uslaner, EM (2010) Segregation, mistrust and minorities. Ethnicities, 10(4): 415-434.

Vervliet, M, De Mol, J, Broekaert, E and Derluyn, I. (2013) 'That I live, that's because 
of her': Intersectionality as framework for unaccompanied refugee mothers.

Advance Access published March 28, 2013. British Journal of Social Work 119.

Wang, H, Schlesinger, M, Wang, H and Hsiao, WC (2009) The flip-side of social capital: The distinctive influences of trust and mistrust on health in rural China. Social Science and Medicine, 68(1): 133-142. 